
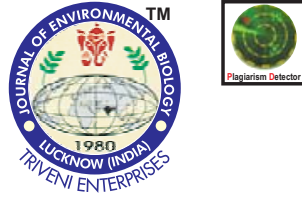

\title{
Interferences of medium and matrix in determination of trace toxic elements using inductively coupled plasma mass spectrometry
}

Authors Info

D. Golui, S.P. Datta* and S.C. Kaushik

Division of Soil Science and Agricultural Chemistry, ICAR-Indian Agricultural Research Institute, New Delhi -110 012, India

${ }^{*}$ Corresponding Author Email : profssac2017@gmail.com

Key words

DTPA

EDTA matrix

Trace element

ICP-mass spectrometry

Publication Info

Paper received : 17.05.2017

Revised received : 11.07.2017

Re-revised received : 22.07.2017

Accepted : 27.07.2017

\section{Abstract}

Aim : In view of scarce information, an attempt was made to assess the effect of different media and matrices on the determination of trace toxic elements using an inductively coupled plasma mass spectrometry (ICP-MS).

Methodology : Standard solutions containing $50 \mu \mathrm{gl}^{-1}$ of trace toxic elements, viz. $\mathrm{Ni}, \mathrm{Pb}, \mathrm{Cd}$, and $\mathrm{Cr}$ were prepared in water, DTPA $(0.005$ and $0.0005 \mathrm{M})$ and EDTA $(0.05$ and $0.005 \mathrm{M})$ separately. The concentration of trace toxic elements in the above mentioned solution was measured with ICP-MS. In another objective, standard solution of $\mathrm{Zn}, \mathrm{Cu}, \mathrm{Fe}, \mathrm{Mn}, \mathrm{Al}, \mathrm{Na}, \mathrm{K}, \mathrm{Ca}$ and $\mathrm{Mg}$ were separately added to the standard solution of $\mathrm{Ni}, \mathrm{Pb}, \mathrm{Cd}, \mathrm{Cr}$, and $\mathrm{As}$, so that final concentration of major and trace toxic elements were $50 \mathrm{mg} \mathrm{I}^{-1}$ and $50 \mathrm{\mu g}$ $\mathrm{I}^{-1}$, respectively. The concentration of standard $\left(50 \mathrm{\mu g} \mathrm{I}^{-1}\right) \mathrm{Ni}, \mathrm{Pb}, \mathrm{Cd}, \mathrm{Cr}$ and $\mathrm{As}$ was measured with ICP-MS. Concentration of these trace toxic elements was also measured in presence of $\mathrm{Zn}, \mathrm{Cu}, \mathrm{Fe}, \mathrm{Mn}, \mathrm{Al}, \mathrm{Na}, \mathrm{K}, \mathrm{Ca}$ and $\mathrm{Mg}$. Hence, the effect of medium and matrix on measurement of trace toxic elements with ICP-MS was ascertained.

Results : Significantly lower concentration of trace toxic element was read under ICP with 10 fold increase in concentration of DTPA and EDTA in solution. For example, Ni concentration decreased from 48.6 to 44.0 $\mu \mathrm{gl}^{-1}$ and 49.2 to $17.6 \mu \mathrm{g} \mathrm{l}^{-1}$ for 10 fold increase in concentration of DTPA and EDTA, respectively. Digestion of sample helped in overcoming this problem. Matrices of elements other than target ones also lowered down the reading under ICP. Extent of suppression in concentration of trace toxic element was relatively higher in the presence of $\mathrm{Na}, \mathrm{Ca}, \mathrm{K}, \mathrm{Mg}$ and $\mathrm{Al}$ as compared to $\mathrm{Zn}, \mathrm{Cu}$, Fe and $\mathrm{Mn}$.

Interpretation : Media and matrices interfered significantly in measurement of trace toxic elements at low concentration $\left(\mu \mathrm{gl}^{-1}\right)$ with ICP-MS.

ICP-MS is used to detect trace toxic elements at even ppt level. Presence of elements other than target ones (matrix) as well as solvents (medium) should not interfere in accurate estimation of trace toxic elements

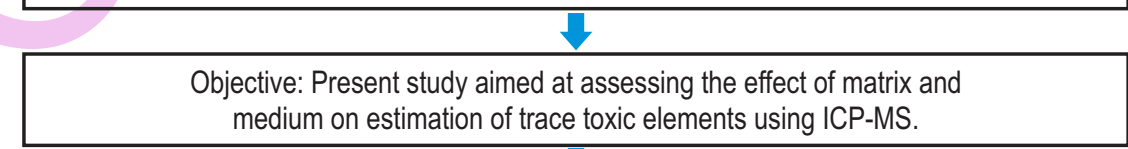

ICP-MS underestimated the concentration of $\mathrm{Ni}, \mathrm{Pb}, \mathrm{Cd}, \mathrm{Cr}$ and $\mathrm{As}$ at $50 \mu \mathrm{gl}^{-1}$ in the presence of $50 \mathrm{mg} \mathrm{l}^{-1}$ of $\mathrm{Zn}, \mathrm{Cu}, \mathrm{Fe}, \mathrm{Mn}, \mathrm{Ca}, \mathrm{Mg}, \mathrm{Na}, \mathrm{K}$, and Al. Similarly, concentrations of trace toxic elements were underestimated in DTPA and EDTA solution.

Media and matrices interfered significantly in measurement of trace toxic elements at low concentration $\left(\mu \mathrm{g} \mathrm{I}^{-1}\right)$ with ICP-MS. 


\section{Introduction}

Inductively coupled plasma mass spectrometry (ICP-MS) not only provides extremely low detection limits in parts per trillion ranges, but also quantifies at high parts per million levels. This unique feature makes the instrument very useful compared to other trace toxic element detection techniques, such as flame atomic absorption spectrometry (FAAS), which has been traditionally used for the detection of higher concentrations. ICPMS is undoubtedly the fastest-growing trace element detection instrument available today. Since its invention in 1983, a fairly large number of systems have been installed worldwide carrying out many varied and diverse applications (Thomas, 2004). The most common one include environmental, geological, biomedical and nuclear application which represent approximately $80 \%$ of the ICP-MS analyses being carried out today. There is no question that the major reason for its unparalleled growth lies in its ability to carry out rapid simultaneous multielement determination at the ultra-trace level. Besides, this instrument is also known for its isotopic capability.

The reproducibility and precision of analytical data as generated by ICP-MS depend on the proper sample preparation to a great extent. It is recommended that aliquot containing trace toxic elements must be acidified (1-2\%) with $\mathrm{HNO}_{3}$. However, effect of such acidification on the solubility of solutes, particularly chelating agents has not been studied so far. Chelating agents like EDTA or DTPA and salts has widely been used for assessing the status of deficiency and toxicity of trace elements in soil (Lindsay and Norvel, 1978; Quevauviller, 1998; Ray et al., 2013; Golui et al., 2014; Meena et al., 2016). Total dissolved solid and relative proportion of trace element have been reported to interfere with the proper functioning of ICP-MS. Usually, relative abundance of trace and ultra-trace elements in aliquot is very low as compared to $\mathrm{Fe}, \mathrm{Al}$ and other alkaline earth elements. In such cases, limited reports indicated that the precise determination of ultra-trace elements in aliquot is affected due to presence of other elements. For example, Liu and Beauchemin (2006) reported that suppression in analyte concentration was due to presence of matrix element in the aliquot. Such report clearly underlines the need of in-depth study on this aspect.

In spite of higher precision, routine use of ICP-MS is not as widespread as that of ICP-optical emission spectrometry mainly because of its greater susceptibility to sample matrix effects (Xiao and Beauchemin, 1994). In soil solution, the dominant cations are $\mathrm{Ca}, \mathrm{Mg}, \mathrm{Na}$, Kand Al. On the other hand, $\mathrm{Zn}$, $\mathrm{Cu}, \mathrm{Fe}$ and $\mathrm{Mn}$ are dominant micronutrients present in the soil solution. Higher concentration of major and micronutrients has been reported to affect the determination of ultra-trace elements under ICP-MS, which are present in ppb or ppt level in soil solution (Gross et al., 2009; Karandashev et al., 2014; Olesik and Jiao, 2017). Matrix effect may also arise from the fact that the sampling of ions in ICP-MS is not a passive process as is the measurement of light in ICP-OES (Xiao and Beauchemin, 1994). The matrix can therefore lead to deposition of solid on the interface, which slowly clogs the sampler orifice, inducing a lowering drift in sensitivity. Although reduction in analyte signal (reading) is in generally observed, presumably owing to space charge effects, over estimations have also been noticed. Internal standardization can, to some extent, compensate for these matrix effects. However, because of additional problem of mass discrimination of analytes, more than one internal standard may be required for adequate compensation. The multi element analysis of samples with complex matrices can therefore be fairly complicated, requiring frequent recalibration and the method of standard addition (Xiao and Beauchemin, 1994).

It is reported that none of the modern ICP-MS method is completely free from analytical problem (Moor et al., 2001), particularly when the concentration is close to the detection limits and resulting in matrix effect due to the wide variation in bulk composition of soil. Devising the ways and means for eliminating both the interferences as arising from medium and matrix is of utmost importance. With this background, the present study was undertaken to study the effect of EDTA and DTPA (media) as well as $\mathrm{Zn}, \mathrm{Cu}, \mathrm{Fe}, \mathrm{Mn}, \mathrm{Ca}, \mathrm{Mg}, \mathrm{Na}, \mathrm{K}$, and $\mathrm{Al}$ (matrices) on determination of trace toxic elements with ICP-MS.

\section{Materials and Methods}

Preparation of standard solution : Stock solution of $1000 \mathrm{mg} \mathrm{l}^{-1}$ for $\mathrm{Zn}, \mathrm{Cu}, \mathrm{Fe}, \mathrm{Mn}, \mathrm{Al}, \mathrm{Na}, \mathrm{K}, \mathrm{Ca}, \mathrm{Mg}, \mathrm{Ni}, \mathrm{Pb}, \mathrm{Cd}, \mathrm{Cr}$ and As was prepared following the standard procedures as outlined by Page (1982). Subsequently, working standards were prepared from stock solution by appropriate dilution and used throughout the experiment.

Preparation of different media : To study the effect of media on determination of trace toxic elements with ICP-MS, standard metal solution was prepared in water, $0.005 \mathrm{M}$ DTPA, $0.0005 \mathrm{M}$ DTPA, $0.05 \mathrm{M}$ EDTA and 0.005M EDTA. Hence, five different media were used throughout the experiment. Standard solution of $\mathrm{Ni}$ was added separately to five different media so that final concentration of Ni could maintain $50 \mu \mathrm{g} \mathrm{I}^{-1}$. Similarly, $50 \mu \mathrm{g} \mathrm{I}{ }^{-1}$ standard solutions were prepared for $\mathrm{Pb}, \mathrm{Cd}$ and $\mathrm{Cr}$ in five media separately. In addition, standard solution containing $50 \mathrm{\mu g} \mathrm{l}^{-1}$ of all trace toxic elements $(\mathrm{Ni}, \mathrm{Pb}, \mathrm{Cd}$ and $\mathrm{Cr}$ ) was prepared in these five media separately. However, 0.005 M DTPA containing $50 \mu \mathrm{g}$ ${ }^{-1}$ of trace toxic element was digested using microwave digestion system (Multiwave ECO, Anton Paar). For this, a $5 \mathrm{ml}$ of aliquot was taken in PTFE-TFM vessel, to which $7 \mathrm{ml}$ suprapure- $\mathrm{HNO}_{3}$ (Merck KGaA, 64271 Darmstadt, Germany) was added and vessel was closed immediately. The operational conditions and the heating program were carried out according to these conditions: a ramp time of $25 \mathrm{~min}$ to reach $180-190^{\circ} \mathrm{C}$ and a hold time of $25 \mathrm{~min}$ at $180-190{ }^{\circ} \mathrm{C}$. After cooling the vessel to room temperature, it was vented and opened. After that Milli-Q water 
was added to the vessel and it was closed and shaken thoroughly to ensure the complete transfer of content. The resultant mixture was filtered through Whatman No. 42 and final volume was made up to $50 \mathrm{ml}$ in a volumetric flask with Milli-Q water containing $1 \%$ suprapure $\mathrm{HNO}_{3}$. Similar procedure without aliquot sample was carried out for preparing a reagent blank.

Preparation of different matrices : To study the effect of matrices i.e., relative proportion of elements in aliquot, standard Zn solution was added separately to standard solution of trace toxic elements ( $\mathrm{Ni}, \mathrm{Pb}, \mathrm{Cd}, \mathrm{Cr}$ and $\mathrm{As}$ ) so that final concentration of $\mathrm{Zn}$ and target elements were $50 \mathrm{mg} \mathrm{I}^{-1}$ and $50 \mathrm{\mu g} \mathrm{l}^{-1}$, respectively. Similarly, a series of standard solution was prepared containing $50 \mathrm{mg} \mathrm{l}^{-1}$ of $\mathrm{Cu}, \mathrm{Fe}, \mathrm{Mn}, \mathrm{Al}, \mathrm{Na}, \mathrm{K}, \mathrm{Ca}$ and $\mathrm{Mg}$ and $50 \mu \mathrm{g}$ $\mathrm{I}^{-1}$ of target trace toxic elements i.e., $\mathrm{Ni}, \mathrm{Pb}, \mathrm{Cd}, \mathrm{Cr}$ and As.

Determination of trace toxic elements and quality control : All the standards were prepared in distilled water and acidified with $\mathrm{HNO}_{3}(1 \% \mathrm{v} / \mathrm{v})$. Suprapure $\mathrm{HNO}_{3}$ of Merck was used throughout the experiment. Trace toxic elements in different experimental solution were measured using a Perkin-Elmer Nexlon ${ }^{T M} 300 X$ inductively coupled plasma mass spectrometer (Waltham, USA) throughout the experiment. For quality control, standard metal solution ( $\mathrm{Ni}, \mathrm{Pb}, \mathrm{Cd}, \mathrm{Cr}$, and $\mathrm{As}$ ) of Merck KGaA, 64271 Darmstadt, Germany, was used to calibrate the ICP-MS. These standards were also included as sample in every batch of 30 samples to ensure the accuracy of analysis. Concentration of trace toxic elements in the prepared standard solution were also measured and compared with commercial standard (Merck KGaA, 64271 Darmstadt, Germany), where no significant difference was observed.

Statistical analysis : The effect of matrices and media on quantification of target metals by ICP-MS was evaluated following Analysis of Variance (ANOVA) method adopting factorial concept through completely randomized design (Snedecor and Cochran, 1967).

\section{Results and Discussion}

Media included acidified water, DTPA and EDTA solution in which $50 \mu \mathrm{gl}^{-1}$ trace toxic elements were measured (Table 1). It is evident that with the increasing concentration of EDTA and DTPA, there was a significant decline in the measured $\mathrm{Ni}$ concentration. Nickel concentration decreased from 48.6 to 44.0 $\mu \mathrm{g} \mathrm{I}^{-1}$ with the increase in concentration of DTPA from 0.0005 to 0.005 M. Similarly, a 10 -fold increase in the concentration of EDTA reduced the Ni concentration from 49.2 to $17.6 \mu \mathrm{g} \mathrm{l}^{-1}$. Abysmally low value of Ni concentration with EDTA was due to precipitation of metal-EDTA chelates in solution containing $1 \%$ $\mathrm{HNO}_{3}$. Critical concentration of $\mathrm{HNO}_{3}$ in EDTA solution was recorded as $0.075 \%$, beyond which precipitation occurred. For analysis of trace toxic elements with ICP-MS, it is recommended that liquid sample should contain $1-2 \% \mathrm{HNO}_{3}$ to prevent adsorption of trace toxic element on the wall of viols as well as clogging in fine capillary tubes carrying sample to plasma. However, to get rid of such interference of chelating agents, aliquot was digested with $\mathrm{HNO}_{3}$ and $\mathrm{Ni}$ concentration in the digested aliquot was recorded as $50.8 \mathrm{\mu g} \mathrm{I}^{-1}$, which is at par with actual concentration. Analysis of Ni in the digested DTPA sample gave correct reading as compared to $0.005 \mathrm{M}$ DTPA, which is not related to precipitation as no precipitation was observed in DTPA sample containing $1 \% \mathrm{HNO}_{3}$. One plausible explanation is that higher concentration of DTPA might have interfered in precise estimation of Ni by leaving residue on plasma. The maximum limit of $0.2 \%$ total dissolve solid in liquid sample intended for ICP-MS analysis is recommended for ICP-MS (USEPA, 2007; ISO, 2009; McCurdy and Proper, 2014; Karandashev et al., 2014). Although, results suggest two options i.e., digestion and dilution. First option would be more suitable for sample having very low concentration of $\mathrm{Ni}$ and second option could be followed, where sample had relatively higher concentration of Ni. Similar result was also recorded for $\mathrm{Pb}$. Concentration of $\mathrm{Pb}$ decreased from 49.0 to 40.2 $\mu \mathrm{gl}^{-1}$ with the increase in the concentration of DTPA from $0.0005 \mathrm{M}$ to $0.005 \mathrm{M}$. In case of EDTA, $50 \%$ reduction in the concentration

Table 1 : Effect of different media on mean reading of trace toxic elements as determined by ICP-MS

\begin{tabular}{|c|c|c|c|c|c|}
\hline \multirow[t]{2}{*}{ Media } & \multirow[b]{2}{*}{$\mathrm{Ni}$} & \multirow[b]{2}{*}{$\mathrm{Pb}$} & \multicolumn{3}{|c|}{ Trace toxic element $\left(\mu \mathrm{g} \mathrm{I}^{-1}\right)$} \\
\hline & & & $\mathrm{Cd}$ & $\mathrm{Cr}$ & Mean $(M)$ \\
\hline & & & \multicolumn{3}{|l|}{ Untreated } \\
\hline Water & 49.5 & 51.1 & 48.3 & 48.7 & 49.4 \\
\hline 0.005 M DTPA & 44.0 & 40.2 & 45.2 & 30.3 & 39.9 \\
\hline \multirow[t]{2}{*}{$0.05 \mathrm{M}$ EDTA } & 17.6 & 22.3 & 18.0 & 24.9 & 20.7 \\
\hline & & & \multicolumn{3}{|l|}{ Treated } \\
\hline \multicolumn{2}{|c|}{ 0.0005M DTPA (Diluted) } & 48.6 & 49.0 & 45.7 & 46.247 .4 \\
\hline \multicolumn{2}{|c|}{0.005 M EDTA (Diluted) } & 49.2 & 49.4 & 43.2 & 42.146 .0 \\
\hline \multicolumn{2}{|c|}{0.005 M DTPA (Digested) } & 50.8 & 51.6 & 48.3 & 48.649 .8 \\
\hline \multirow[t]{2}{*}{ Mean (E) } & 43.3 & 43.9 & 41.5 & 40.1 & \\
\hline & $\operatorname{LSD}(P=0.05)$ & Medium $=0.51$ & Element $=0.46$ & $\mathrm{Mec}$ & \\
\hline
\end{tabular}

Note: $50 \mu \mathrm{gl}^{-1}$ standard solution of $\mathrm{Ni}, \mathrm{Pb}, \mathrm{Cd}$, and $\mathrm{Cr}$ were prepared separately in different media and $0.05 \mathrm{M}$ EDTA was not digested as major portion of EDTA was precipitated 
of $\mathrm{Pb}$ was recorded in $0.05 \mathrm{M}$ EDTA as compared to $0.005 \mathrm{M}$ EDTA. Digestion of samples with $\mathrm{HNO}_{3}$ led to precise estimation

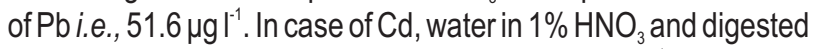
$0.005 \mathrm{M}$ DTPA produced similar results i.e., $48.3 \mu \mathrm{gl}^{-1}$. There was no significant difference in reading of $\mathrm{Cd}$ recorded in $0.0005 \mathrm{M}$ and $0.005 \mathrm{M}$ DTPA medium. However, concentration of $\mathrm{Cd}$ was decreased by $58.3 \%$ in $0.05 \mathrm{M}$ EDTA as compared to $0.005 \mathrm{M}$ EDTA. Significant reduction in $\mathrm{Cr}$ concentration was recorded in $0.005 \mathrm{M}$ DTPA solution as compared to $0.0005 \mathrm{M}$ DTPA solution. Digestion of $0.005 \mathrm{M}$ DTPA resulted into $48.7 \mu \mathrm{g} \mathrm{I} \mathrm{I}^{-1} \mathrm{Cr}$, which is very close to actual concentration of $50 \mathrm{\mu g} \mathrm{I}^{-1}$.

More or less similar results were obtained for $\mathrm{Ni}$ in different media as obtained in case of individual solution. Increase concentration of DTPA from $0.0005 \mathrm{M}$ to $0.005 \mathrm{M}$ resulted into $23.9 \%$ reduction in concentration of Ni. Similarly, in EDTAmedium at higher concentration i.e., $0.05 \mathrm{M} \mathrm{in} 1 \% \mathrm{HNO}_{3}$, the concentration of Ni was recorded as $24.1 \mathrm{\mu g} \mathrm{I}^{-1}$. In multielement solution, $50 \mathrm{\mu g} \mathrm{I}^{-1}$ $\mathrm{Ni}$ read as $49.9 \mu \mathrm{g} \mathrm{I}^{-1}$ on ICP-MS after digestion. Significant reduction in concentration of $\mathrm{Pb}, \mathrm{Cd}$ and $\mathrm{Cr}$ compared to their actual concentration were recorded in all media except water in $\mathrm{HNO}_{3}$ and digested DTPA. To overcome the possible interferences within the trace toxic element as well as medium effect, digestion of medium is required before taking the reading through ICP-MS. Indeed concentrations of $\mathrm{Pb}, \mathrm{Cd}$ and $\mathrm{Cr}$ in digested DTPAmedium were recorded as 50.4, 49.7 and $48.8 \mu \mathrm{g} \mathrm{I}$ ${ }^{1}$, respectively (Table 2).

Such results have important practical implications as both DTPA and EDTA have been widely used as extractant in soil testing. DTPA $(0.005 \mathrm{M})$ soil test is used for assessing the deficiency of micronutrient cations as well as level of metals in moderately contaminated soils (Lindsay and Norvell, 1978; Norvell, 1984). While, European Commission standardised and suggested the use of $0.05 \mathrm{M}$ EDTA for assessing available metal in polluted soil (Quevauviller, 1998).

To elucidate the effect of matrices on precise measurement of trace toxic element by ICP-MS, standard solution of $\mathrm{Zn}, \mathrm{Cu}, \mathrm{Fe}, \mathrm{Mn}, \mathrm{Ca}, \mathrm{Mg}, \mathrm{Na}, \mathrm{K}$, and Al (major elements) were added separately to each standard solution of $\mathrm{Ni}, \mathrm{Pb}, \mathrm{Cd}, \mathrm{Cr}$ and As (trace toxic elements) so that final concentration of major and trace toxic elements were $50 \mathrm{mg} \mathrm{l}^{-1}$ and $50 \mathrm{\mu g} \mathrm{I}^{-1}$, respectively. The results indicated that in the presence of $50 \mathrm{mg} \mathrm{l}^{-1} \mathrm{Ca}$, concentration of $\mathrm{Ni}$ was recorded as $44.0 \mu \mathrm{g} \mathrm{I}^{-1}$ (Table 3). Karandashev et al. (2014) reported that the signal from Co and Se

Table 2 : Effect of different media on mean reading of trace toxic element in multielement solution of $50 \mu \mathrm{g} \mathrm{I}^{-1}$ under ICP-MS

\begin{tabular}{|c|c|c|c|c|c|}
\hline \multirow[t]{2}{*}{ Media } & \multicolumn{5}{|c|}{ Trace toxic element $\left(\mu \mathrm{gl}^{-1}\right)$} \\
\hline & $\mathrm{Ni}$ & $\mathrm{Pb}$ & $\mathrm{Cd}$ & $\mathrm{Cr}$ & Mean (M) \\
\hline \multicolumn{6}{|c|}{ Untreated } \\
\hline Water & 47.3 & 48.8 & 47.6 & 48.0 & 47.9 \\
\hline 0.005 M DTPA & 39.6 & 34.4 & 37.0 & 45.3 & 39.1 \\
\hline 0.05 M EDTA & 24.1 & 22.3 & 20.3 & 21.3 & 22.0 \\
\hline \multicolumn{6}{|c|}{ Treated } \\
\hline 0.0005M DTPA (Diluted) & 49.1 & 43.7 & 45.7 & 40.2 & 44.7 \\
\hline 0.005 M EDTA (Diluted) & 48.5 & 44.5 & 44.5 & 42.2 & 44.9 \\
\hline 0.005 M DTPA (Digested) & 49.9 & 50.4 & 49.7 & 48.8 & 49.7 \\
\hline Mean (E) & 43.1 & 40.7 & 40.8 & 37.8 & \\
\hline $\operatorname{LSD}(P=0.05)$ & \multicolumn{3}{|c|}{ Medium $=0.62 \quad$ Element $=0.57$} & \multicolumn{2}{|c|}{ Medium $x$ Element $=1.39$} \\
\hline
\end{tabular}

Note: Solution containing $50 \mu \mathrm{I} \mathrm{I}^{-1} \mathrm{Ni}, \mathrm{Pb}, \mathrm{Cd}$, and $\mathrm{Cr}$ (multielement mixture) was prepared in different media and $0.05 \mathrm{M}$ EDTA was not digested as major portion of EDTA was precipitated

Table 3 : Effect of matrix on mean reading of trace toxic elements as determined by ICP-MS

\begin{tabular}{|c|c|c|c|c|c|c|c|c|c|c|c|}
\hline \multicolumn{6}{|c|}{ Trace toxic element $\left(\mu \mathrm{gl}^{-1}\right)$} & \multicolumn{6}{|c|}{ Matrix $\left(50 \mathrm{mg} \mathrm{l}^{-1}\right)$} \\
\hline & 0 & $\mathrm{Zn}$ & $\mathrm{Cu}$ & $\mathrm{Fe}$ & $\mathrm{Mn}$ & $\mathrm{Ca}$ & $\mathrm{Mg}$ & $\mathrm{Na}$ & $\mathrm{K}$ & Al & Mean (M) \\
\hline $\mathrm{Ni}$ & 49.5 & 48.2 & 48.3 & 47.3 & 46.2 & 44.0 & 45.1 & 44.6 & 45.0 & 45.6 & 46.4 \\
\hline $\mathrm{Pb}$ & 50.1 & 42.7 & 42.2 & 46.8 & 45.2 & 40.4 & 41.6 & 39.5 & 40.8 & 42.7 & 43.2 \\
\hline $\mathrm{Cd}$ & 48.3 & 45.9 & 44.4 & 44.0 & 43.7 & 42.0 & 41.8 & 41.0 & 41.5 & 42.1 & 43.5 \\
\hline $\mathrm{Cr}$ & 48.7 & 40.6 & 40.5 & 40.3 & 38.7 & 37.7 & 39.5 & 39.0 & 38.9 & 39.8 & 40.4 \\
\hline As & 49.2 & 39.6 & 41.6 & 42.5 & 40.5 & 38.0 & 38.3 & 39.9 & 39.9 & 39.5 & 40.9 \\
\hline Mean (M) & 49.2 & 43.4 & 43.4 & 44.2 & 42.9 & 40.4 & 41.3 & 40.8 & 41.2 & 41.9 & \\
\hline
\end{tabular}

Note: $50 \mu \mathrm{g} \mathrm{I}^{-1}$ standard solution of $\mathrm{Ni}, \mathrm{Pb}, \mathrm{Cd}, \mathrm{Cr}$, and As containing $50 \mathrm{mg} \mathrm{l}^{-1} \mathrm{Zn}, \mathrm{Cu}, \mathrm{Fe}, \mathrm{Mn}, \mathrm{Ca}, \mathrm{Mg}, \mathrm{Na}, \mathrm{K}$, and Al were prepared separately 
were suppressed by $20 \%$ at a concentration of manganese in the solution of $2 \mathrm{gl}^{-1}$. Lower concentration of Ni i.e., $44.6 \mu \mathrm{gl}^{-1}$ was also recorded in the presence of $\mathrm{Na}$ as compared to its actual concentration. Nickel concentration was measured as 45.1, 45.0 and $45.6 \mu \mathrm{gl}^{-1}$ in the presence of $\mathrm{Mg}, \mathrm{K}$ and Al, respectively. Least matrix effect was exhibited by $\mathrm{Zn}, \mathrm{Cu}$, Fe and Mn on concentration of $\mathrm{Ni}$ and concentration of $\mathrm{Ni}$ in the presence of $\mathrm{Zn}, \mathrm{Cu}, \mathrm{Fe}$ and $\mathrm{Mn}$ were recorded as $48.2,48.3,47.3$ and $46.2 \mathrm{gg} \mathrm{I}^{-1}$, respectively. Beuchemin et al. (1987) studied the effect of $0.01 \mathrm{M} \mathrm{Li}, \mathrm{Na}, \mathrm{K}, \mathrm{Cs}$, $\mathrm{Mg}, \mathrm{Ca}, \mathrm{B}, \mathrm{Al}$ and $\mathrm{U}$ on $50 \mu \mathrm{g} \mathrm{l} \mathrm{I}^{-1}$ concentration of $\mathrm{V}, \mathrm{Cr}, \mathrm{Mn}, \mathrm{Ni}, \mathrm{Co}$, $\mathrm{Cu}, \mathrm{Zn}, \mathrm{Cd}$ and $\mathrm{Pb}$ and found that easily ionized elements, such as $\mathrm{Na}, \mathrm{Mg}, \mathrm{K}, \mathrm{Ca}$ and $\mathrm{Cs}$ can enhance analyte signal, while others such as Al, B, and $\mathrm{U}$ caused suppression for analytes in ICP-MS. However, in the present investigation such enhancement effect was not observed. More or less similar trend was recorded for $\mathrm{Pb}$, $\mathrm{Cd}, \mathrm{Cr}$ and As. Suppression in the concentration of $\mathrm{Pb}$ was highest $\left(39.5 \mathrm{\mu g} \mathrm{l}^{-1}\right)$ in the presence of Na matrix. McCurdy and Proper (2014) found decrease in the concentration of $\mathrm{Cd}, \mathrm{Ni}, \mathrm{Cr}$ and As when solutions containing $25 \% \mathrm{NaCl}$ matrix. Previous studies have reported that due to higher concentration in sample, matrix effects of $\mathrm{Na}$ are common in many important sample types. Olesik and Jiao (2017) reported that presence of $5 \mathrm{mM} \mathrm{Na}$ or $5 \mathrm{mM}$ $\mathrm{Cu}$ induced less than a $10-15 \%$ change in analyte ion ( $\mathrm{Ni}$, As and Cd) concentration. Olivares and Houk (1986) confirmed that interference was most serious for the most easily ionised matrix elements in the following order $\mathrm{Na}>\mathrm{Mg}>\mathrm{Br}>\mathrm{Cl}$. The relative order of matrix element for suppression of $\mathrm{Pb}$ concentration was $\mathrm{Na}>$ $\mathrm{Ca}>\mathrm{K}>\mathrm{Mg}>\mathrm{Cu}>\mathrm{Zn}>\mathrm{Al}>\mathrm{Mn}>\mathrm{Fe}$. In case of $\mathrm{Cd}$, highest matrix effect was observed by $\mathrm{Na}\left(41.0 \mu \mathrm{g} \mathrm{I} \mathrm{I}^{-1}\right)$. The interferences of $\mathrm{Na}, \mathrm{K}$, $\mathrm{Ca}, \mathrm{Mg}$, and $\mathrm{Al}$ on concentration of $\mathrm{Cd}$ were higher as compared to $\mathrm{Zn}, \mathrm{Cu}, \mathrm{Fe}$ and $\mathrm{Mn}$. Due to presence of matrix elements more than $25 \%$ reduction in concentration of $\mathrm{Cr}$ was recorded. Similarly, more than $25 \%$ reduction in reading of As was recorded in the presence of $\mathrm{Zn}, \mathrm{Ca}, \mathrm{Mg}, \mathrm{Na}$, Kand Al.

Karandashev et al. (2014) and Olesik and Jiao (2017) summarized some general trend in matrix effect as trace analyte ions are subject to more severe matrix effects, heavier matrix elements cause more severe suppression, easily ionized matrix elements cause more suppression than moderately ionized matrix elements, and the absolute amount of matrix element present in the solution rather than the mole ratio of matrix to analyte is important in suppression. Kawaguchi et al. (1990) proposed that the lighter analyte ions are more susceptible to collision loss than the heavier ones in the presence of heavy matrix elements. Vandecasteele et al. (1993) reported a successful and easy way of overcoming the matrix effects due to high concentrations of concomitant elements present in the solution as dilution of samples such that total matrix concentrations are less than $500-1000 \mu \mathrm{g} \mathrm{I}^{-1}$, provided that the analyte elements are still above the detection limit. Calibration using matrix matched standards is also a practical method of correction, if the composition of the sample is known and high purity standards are available (Gross et al., 2009; Karandashev et al., 2014; Olesik and Jiao, 2017). Such results are of utmost importance as there is possibility of underestimation or over estimation of trace toxic elements under ICP-MS in the presence of dominant elements in soil solution. User should have fare idea of such interference (matrix) if not quantitatively, at least on qualitative term. Such knowledge definitely will help user in preparation of sample for ICP-MS. Based on such information, the capability of ICP-MS ma by improved by manufacturer.

Media and matrices interfered significantly in measurement of trace toxic elements at low concentration with ICP-MS. Such results should have important practical implication in precise measurement of trace toxic elements in soil extract using ICP-MS. As soil extract may contain more than 100 elements. Besides, DTPA and EDTA solution are commonly used extractants for assessing status of micronutrients and trace toxic elements in soil.

\section{Acknowledgment}

This study was made possible by the financial support provided by the Indian Council of Agricultural Research in the form of a Senior Research Fellowship to the first author during his Ph.D. programme.

\section{References}

Beauchemin, D., J.W. McLaren and S.S. Herman: Study of the effects of concomitantelements in inductively coupled plasma mass spectrometry. SpectrochimActa PartB:At. Spect., 42, 467-490 (1987).

Golui, D., S.P. Datta, R.K. Rattan, B.S. Dwivedi and M.C. Meena: Predicting bioavailability of metals from sludge amended soils. Environ. Monit. Assess., 186, 8541-8553 (2014).

Gross, C.T., S.M. McIntyre and R.S. Houk: Reduction of matrix effects in inductively coupled plasma mass spectrometry by flow injection with an unshielded torch. Anal. Chem., 81, 4898-4905 (2009).

International Organization for Standardization (ISO) 17294-2:2003 Water quality -Application of Inductively Coupled Plasma Mass Spectrometry (ICP-MS) - Part 2: Determination of 62 Elements (Geneva, Switzerland, 2009).

Karandashev, V.K., A.Yu. Leykin and K.V. Zhernokleeva: Reduction of matrix effects in ICP MS by optimizing settings of ion optics. Anal. Chem., 69, 26-34 (2014).

Kawaguchi, H., T. Tanaka, T. Nakamura, M. Morishita and A. Mizuiki: Matrix Effects in inductively coupled plasma mass spectrometry. Anal. Sci., 3, 305-308 (1987).

Lindsay, W.L and W.A. Norvell: Development of a DTPA soil test for zinc, iron, manganese and copper. Soil Sci. Soc. Am. J., 42, 421-428 (1978).

Liu, S. and D. Beauchemin: Effect of methanol and sodium dodecylsulfate on radial profiles of ion abundance in inductively coupled plasma mass spectrometry. Spectrochim. Acta Part B: At. Spect., 61, 319-325 (2006).

McCurdy, E and E. Proper: Improving ICP-MS analysis of samples containing high levels of total dissolved solids. Sepect., 29, (2014).

Meena, R., S.P. Datta, D. Golui, B.S. Dwivedi and M.C. Meena: Long term impact of sewage irrigation on soil properties and assessing risk in 
relation to transfer of metals to human food chain. Environ. Sci. Pollut. Res., 23, 14269-14283 (2016).

Moor, C., L, Theopisti and J.D. Volker: Determination of heavy metals in soils, sediments and geological materials by ICP-AES and ICPMS. Mikrochim. Acta, 136, 123-128 (2001).

Norvell, W.A.: Comparison of chelating agents as extractants for metals in diverse soil materials. Soil. Sci. Soc. Am. J., 48, 1285-1292(1984).

Olesik, J.W. and S. Jiao: Matrix effects using an ICP-MS with a single positive ion lens and ground stop: analyte mass dependent?. J. Anal.At. Spectrom., 32, 951-966 (2017).

Olivares, J.A. and R.S. Houk: Suppression of analyte signal by various concomitant salts in inductively coupled plasma mass spectrometry. Anal. Chem., 58, 20-25 (1986).

Page, A.L., R.H. Miller and D.R. Keeney: Methods of Soil Analysis Part 2, Chemical and microbiological properties. Agron. Monogr. Second edition. ASA and SSSA, Madison, WI (1982).

Quevauviller, P.H.: Operationally defined extraction procedures for soil and sediment analysis. Trends Analyt. Chem., 17, 289-298 (1998).
Ray, P., S.K. Singhal, S.P. Datta and R.K. Rattan: Evaluation of suitability of chemical extractants for assessing available zinc in acid and alkaline soils amended with farmyard manure and sludge. Agrochimica, 4, 348-362 (2013).

Snedecor, G.W and W.G. Cochran: In: Statistical Methods, $7^{\text {th }}$ Ed., The Lowa State University. Press America, Lowa, USA(1967).

Thomas, R.: Practical guide to ICP-MS, Mercel Dekker Inc., New York, Basel (2004).

United States Environmental Protection Agency (USEPA): Method 6020Ainductively coupled plasma mass spectrometry. Retrieved from http://www.epa.gov/wastes/hazard/testmethods/sw846 (2007).

Vandecasteele, C., H. Vanhoe and R. Dams: Inductively coupled plasma mass spectrometry of biological samples, Invited lecture. J. Anal. At. Spectrom., 8, 781-786 (1993).

Xiao, $G$ and D. Beauchemin: Reduction of matrix effects and mass discrimination ininductively coupled plasma mass spectrometry with optimized argon-nitrogen plasmas. J. Anal. At. Spect., 9, 509518(1994). 